\title{
Breast cancer surgery in elderly patients: postoperative complications and survival
}

\author{
Nicola Rocco ${ }^{1}$, Corrado Rispoli², Gennaro Pagano ${ }^{3}$, Giuseppe Rengo ${ }^{3}$, Rita Compagna ${ }^{4}$, Michele Danzi ${ }^{4}$, \\ Antonello Accurso ${ }^{4}$, Bruno Amato ${ }^{4^{*}}$ \\ From 26th National Congress of the Italian Society of Geriatric Surgery \\ Naples, Italy. 19-22 June 2013
}

\begin{abstract}
Aims and background: Old age is associated with comorbidity and decreased functioning which influences treatment decisions in elderly breast cancer patients. The purpose of this study was to identify risk factors for complications after breast cancer surgery in elderly patients, and to assess mortality in patients with postoperative complications.

Methods: We retrospectively considered all female patients aged 65 years and older with invasive and in situ breast cancer who were diagnosed and treated between 1997 and 2012 in the Department of General and Geriatric Surgery of the University of Naples "Federico II".

Results and conclusion: 449 patients received surgery, of whom 18,2\% $(n=82)$ developed one or more postoperative complications. The odds ratio of having postoperative complications show an increase with age, reaching statistical significance only for patients older than 85 [OR 5,75 (95\% confidence interval 2,38-14,04); $p<$ 0,001 ]. Number of concomitant diseases [OR 2,51 (95\% Cl 1,17-5,45); $p=0,01$ for 3 or more concomitant diseases] and polypharmacy [OR $16,7(95 \% \mathrm{Cl} 9,12-30,58) ; \mathrm{p}<0,0001)$ are associated to an increased risk of postoperative complications. Overall survival was worse in patients with postoperative complications [HR 2,06 (95\% Cl 1,52-2,70), $p<0,001]$. This increased risk of mortality is probably due to geriatric parameters such as comorbidity or poor physical function, more than to higher complication rates.
\end{abstract}

\section{Introduction}

In developed countries, $40 \%$ of breast cancer patients are older than 65 years of age at diagnosis and this percentage is increasing [1]. Old age is predictive for comorbidity and decreased functioning $[2,3]$. Therefore, these factors might influence treatment decisions in elderly breast cancer patients. Previous studies have shown that elderly breast cancer patients receive less aggressive treatment [4] and have a higher disease-specific mortality, even with $65 \%$ of breast cancer patients above 75 years dying from other causes than breast cancer [5].

The most recent guidelines of the International Society of Geriatric Oncology and the European Society

\footnotetext{
* Correspondence: bramato@unina.it

${ }^{4}$ Department of General, Geriatric, Oncologic Surgery and Advanced

Technologies, University "Federico II" of Naples, Naples, Italy

Full list of author information is available at the end of the article
}

of Breast Cancer Specialists (EUSOMA) advise breast conserving surgery with whole-breast radiotherapy or mastectomy followed by postoperative radiotherapy in selected patients as standard care for elderly breast cancer patients [6]. However, the National Comprehensive Cancer Network guidelines state that omission of radiotherapy may be considered in patients of 70 years or older with stage I estrogen receptor-positive breast cancer who undergo a lumpectomy with negative margins and are receiving endocrine therapy [7]. This shows that there is still no consensus on how to treat elderly breast cancer patients. Also, elderly patients are often not treated according to guidelines [8,9]. Comorbid conditions and frailty are, besides age and patient and physician's preference, important reasons to deviate from the guidelines $[10,11]$. Besides, treatment strategies for elderly breast cancer patients are mostly not evidence-based
C Biomed Central

C 2013 Rocco et al; licensee BioMed Central Ltd. This is an open access article distributed under the terms of the Creative Commons Attribution License (http://creativecommons.org/licenses/by/2.0), which permits unrestricted use, distribution, and reproduction in any medium, provided the original work is properly cited. 
because elderly are often not included in clinical trials due to age restrictions or comorbidity [12].

Breast surgery is generally considered as low-morbidity surgery [13]. However, a variety of complications can occur with serious consequences. For example, surgical site infections can lead to increased morbidity, additional costs and delay of postoperative adjuvant therapies [13].

In order to develop evidence-based guidelines for tailored care of breast cancer in the elderly, it is important to investigate the occurrence of complications of surgery in this specific group. Only few studies concerning postoperative complications in elderly breast cancer patients have been performed, often with a limited number of patients $[11,14,15]$. Therefore, the objective of this study was to identify risk factors for postoperative complications in elderly breast cancer patients, and to evaluate overall survival in patients with postoperative complications compared with patients without postoperative complications.

\section{Methods}

We considered all consecutive female patients aged 65 years and older with invasive and in situ breast cancer who were diagnosed and treated between 1997 and 2012 in the Department of General and Geriatric Surgery of the University of Naples "Federico II".

We reviewed the charts of these patients and collected information on specific treatments, comorbidities, adverse events, geriatric parameters, body mass index (BMI), smoking and mortality.

For this study, all patients with breast cancer stage I-IV and in situ of all histological subtypes who were treated with breast conserving surgery or mastectomy were included. If patients received breast-conserving surgery (BCS) followed by mastectomy, the most extensive surgery was used for analyses. Stage was described using the pathological tumor-node-metastasis (TNM) classification, as valid in the year of diagnosis. If the pathological stage was missing, clinical stage was used. Axillary surgery was defined as a sentinel node procedure or an axillary lymph node dissection. Again, the most extensive axillary surgery was used for the analyses.

To compare different age groups, patients were categorized into five groups: 65-69, 70-74, 75-79, 80-84, and 85 years or older.

Number of concomitant diseases was categorized in four groups: no concomitant disease, 1 concomitant disease, 2 concomitant diseases and 3 or more concomitant diseases [16]. BMI was analyzed in three groups: $<20$, $20-25$, and $>25$.

In case of missing data, patients were not excluded from the analyses, but analyzed in a separate group (unknown).

The possible postoperative complications were wound infections (including abscesses), bleeding, hematoma, seroma, anemia, cardiovascular complications, thromboembolisms and other complications. The primary outcome was defined as having one or more of these complications.

\section{Statistical analyses}

All statistical analyses were two-sided. A p value smaller than 0.05 was considered as significant.

The following risk factors for having at least one postoperative complication were assessed in univariable logistic regression models: age (in groups per 5 years), stage according to the TNM-classification, most extensive surgery, most extensive axillary surgery, number of comorbid conditions, polypharmacy (5 or more types of drugs per day), neoadjuvant treatment, BMI, and smoking at time of surgery.

\section{Results}

\section{Patient characteristics}

Overall, 449 patients of 65 years and older with invasive and in situ breast cancer underwent BCS or mastectomy and were included for analyses. Patient characteristics are shown in Table 1.

Most patients (72\%) were treated with mastectomy. The majority of patients $(74.8 \%)$ had at least one concomitant disease. Few patients (3.0\%) received neoadjuvant treatment. $21 \%$ of the patients used 5 or more types of drugs per day. BMI values were missing in 224 patients (49.8\%) and data about smoking were missing in 142 patients (31.6\%). Median follow up was 7.5 years (range $0.01-15.0)$.

\section{Postoperative complications}

Overall, $18.2 \%$ of patients developed 1 or more postoperative complications (Table 2). The most frequent complications were seroma $(\mathrm{n}=21)$ and wound infection $(\mathrm{n}=17)$.

As shown in Table 3, the odds ratio (OR) for developing a postoperative complication increased with age (OR for patients aged $>85$ years was 5.75 (95\% confidence interval 2.38-14.04, $\mathrm{p}<0.001)$ in a univariable logistic regression model).

A higher number of concomitant diseases was associated with a higher risk of postoperative complications (patients without concomitant disease functioned as a reference; OR was 1.67 (95\% CI 0.74-3.80), 1.79 (95\% CI $0.80-4.07)$ and 2.51 (95\% CI 1.17-5.45; p $=0.01)$ in patients with 1, 2 and 3 or more concomitant diseases, respectively).

Similarly, polypharmacy was strongly associated with risk of complications (OR 16.7 (95\% CI 9.12-30.58), p < 0.0001).

Furthermore, patients who received a mastectomy and patients who underwent axillary lymph node dissection 
Table 1 Patients characteristics.

\begin{tabular}{|c|c|c|}
\hline PATIENTS' CHARACTERISTICS & n (449) & $\%$ \\
\hline MEDIAN AGE (range) & $76.0(65-92)$ & \\
\hline \multicolumn{3}{|l|}{$\overline{\mathrm{AGE}}$} \\
\hline $65-69$ & 131 & $29,5 \%$ \\
\hline $70-74$ & 114 & $25,1 \%$ \\
\hline $75-79$ & 87 & $19,3 \%$ \\
\hline $80-84$ & 68 & $15,2 \%$ \\
\hline$>85$ & 49 & $10,9 \%$ \\
\hline \multicolumn{3}{|l|}{ N OF CONCOMITANT DISEASE } \\
\hline$\overline{0}$ & 113 & $25,2 \%$ \\
\hline 1 & 112 & $25,0 \%$ \\
\hline 2 & 106 & $23,6 \%$ \\
\hline$>=3$ & 118 & $26,2 \%$ \\
\hline \multicolumn{3}{|l|}{ TNM STAGE } \\
\hline IN SITU & 17 & $3,9 \%$ \\
\hline I & 168 & $37,5 \%$ \\
\hline$\|$ & 180 & $40,1 \%$ \\
\hline III & 39 & $8,8 \%$ \\
\hline $\mathrm{IV}$ & 4 & $1,0 \%$ \\
\hline UNKNOWN & 41 & $8,7 \%$ \\
\hline \multicolumn{3}{|l|}{ NEOADJUVANT TREATMENT } \\
\hline NO NEOADJUVANT TREATMENT & 436 & $97 \%$ \\
\hline NEOADJUVANT CHEMOTHERAPY & 13 & $3 \%$ \\
\hline \multicolumn{3}{|l|}{ BREAST SURGERY } \\
\hline BREAST CONSERVING SURGERY & 125 & $28 \%$ \\
\hline MASTECTOMY & 324 & $72 \%$ \\
\hline \multicolumn{3}{|l|}{$\overline{\text { AXILLARY SURGERY }}$} \\
\hline NO AXILLARY SURGERY & 40 & $9 \%$ \\
\hline SENTINEL NODE BIOPSY & 180 & $40 \%$ \\
\hline AXILLARY LYMPH NODE DISSECTION & 229 & $51 \%$ \\
\hline \multicolumn{3}{|l|}{$\overline{\mathrm{BMI}}$} \\
\hline$<20$ & 4 & $1 \%$ \\
\hline $20-25$ & 86 & $19,1 \%$ \\
\hline$>25$ & 135 & $30,1 \%$ \\
\hline UNKNOWN & 224 & $49,8 \%$ \\
\hline \multicolumn{3}{|l|}{ POLYPHARMACY } \\
\hline$\overline{\mathrm{NO}}$ & 354 & $79 \%$ \\
\hline$\overline{Y E S}$ & 95 & $21 \%$ \\
\hline \multicolumn{3}{|l|}{ SMOKING AT TIME OF DIAGNOSIS } \\
\hline$\overline{\mathrm{NO}}$ & 276 & $61,5 \%$ \\
\hline$\overline{\mathrm{YES}}$ & 31 & $6,9 \%$ \\
\hline UNKNOWN & 142 & $31,6 \%$ \\
\hline
\end{tabular}

had more complications than patients who were treated with breast conserving surgery and less extensive axillary surgery.

Smoking increased the odds for developing a complication with an OR of 2.75 (95\% CI 1.14-6.54, p < 0.05).
There was no significant association between BMI and postoperative complications.

Overall survival was worse in patients with postoperative complications [HR 2,06 (95\% CI 1,52-2,70), p < 0,001 ] (Table 4). This increased risk of mortality is probably due to geriatric parameters such as comorbidity or poor physical function, more than to higher complication rates.

\section{Discussion}

This study shows that the number of concomitant diseases and polypharmacy are strongly related to the occurrence of postoperative complications in elderly breast cancer patients.

Patients treated with mastectomy had more complications than patients who received breast conserving surgery.

Elderly patients had complications more often, but after adjustment for tumor stage, comorbidity, and treatment, only a trend for increasing risk of complications in higher age groups was observed.

Overall survival was worse in patients with one or more postoperative complications.

The increased risk for early and late overall mortality is probably not due to the complications in itself, but can be explained by the frail state of the patients who develop postoperative complications, since comorbidity in itself increases the risk of mortality in elderly breast cancer patients $[17,18]$.

Concerning the impact of comorbidity on developing postoperative complications, Houterman et al. [15] concluded from an observational study that comorbidity and age did not influence the occurrence of complications after treatment. The study included only 154 patients aged 70 years or older, and investigated complications of all types of therapy in the first year after diagnosis. Also, patients who did not receive surgery were included in this study. Therefore, this study differs considerably from the current study, which might explain the differences in outcome. Another study by JanssenHeijnen et al. [14] also found no association between comorbidity and postoperative complications. Again, this study included only 490 patients with breast cancer, of whom only 192 were older than 65 . Since the impact of comorbid disease is the highest in the eldest elderly, this might explain the differences with the current study.

A recent Danish study [19] found that older age and mastectomy increases the risk of re-operation due to bleeding in breast cancer surgery. These results were confirmed in the current study.

Another study [20] found that BMI $>25$, diabetes, and smoking were predictors of wound complications. In the current study, BMI was not related to risk of postoperative 
Table 2 Complications in different age groups.

\begin{tabular}{|c|c|c|c|c|c|c|}
\hline & TOTAL & $65-69$ & $70-74$ & $75-79$ & $80-84$ & $>=85$ \\
\hline ALL COMPLICATIONS & $82(18,2 \%)$ & $13(9,9 \%)$ & $15(13,2 \%)$ & $17(19,5 \%)$ & $18(26,5 \%)$ & $19(38,8 \%)$ \\
\hline WOUND INFECTION & $17(3,8 \%)$ & 3 & 4 & 4 & 3 & 3 \\
\hline BLEEDING & $14(3,2 \%)$ & 4 & 2 & 2 & 3 & 3 \\
\hline HEMATOMA & $14(3,2 \%)$ & 3 & 2 & 4 & 3 & 2 \\
\hline SEROMA & $21(4,8 \%)$ & 2 & 4 & 5 & 4 & 6 \\
\hline ANEMIA & $2(0,4 \%)$ & 0 & 0 & 0 & 1 & 1 \\
\hline CARDIOVASCULAR COMPLICATION & $8(1,4 \%)$ & 0 & 2 & 2 & 2 & 2 \\
\hline THROMBO-EMBOLISM & $4(1,0 \%)$ & 1 & 1 & 0 & 1 & 1 \\
\hline OTHER COMPLICATIONS & $2(0,4 \%)$ & 0 & 0 & 0 & 1 & 1 \\
\hline
\end{tabular}

Table 3 Association between patient, tumor characteristics, treatment and occurrence of postoperative complications.

\begin{tabular}{|c|c|c|c|c|}
\hline & N OF PATIENTS WITH COMPLICATION (\%) & OR & $95 \% \mathrm{Cl}$ & $p$ value \\
\hline \multicolumn{5}{|l|}{$\overline{\mathrm{AGE}}$} \\
\hline $65-69$ & $13(9,9 \%)$ & Ref & & \\
\hline $70-74$ & $15(13,2 \%)$ & 1,37 & $0,58-3,24$ & ns \\
\hline $75-79$ & $17(19,5 \%)$ & 2,20 & $0,95-5,16$ & ns \\
\hline $80-84$ & $18(26,5 \%)$ & 3,27 & $1,40-7,72$ & 0,004 \\
\hline$>=85$ & $19(38,8 \%)$ & 5,75 & $2,38-14,04$ & $<0,001$ \\
\hline \multicolumn{5}{|l|}{ N OF CONCOMITANT DISEASE } \\
\hline 0 & $13(12,0 \%)$ & Ref & & \\
\hline 1 & $20(18,3 \%)$ & 1,67 & $0,74-3,80$ & ns \\
\hline 2 & $20(18,5 \%)$ & 1,79 & $0,80-4,07$ & ns \\
\hline$>=3$ & $29(24,6 \%)$ & 2,51 & $1,17-5,45$ & 0,01 \\
\hline \multicolumn{5}{|l|}{ POLYPHARMACY } \\
\hline $\mathrm{NO}$ & $27(7,6 \%)$ & Ref & & \\
\hline YES & $55(57,9 \%)$ & 16,65 & $9,12-30,58$ & $<0.0001$ \\
\hline \multicolumn{5}{|l|}{ BREAST SURGERY } \\
\hline BREAST CONSERVING SURGERY & $29(23,2 \%)$ & Ref & & \\
\hline MASTECTOMY & $53(16,4 \%)$ & 0.65 & $0,38-1,11$ & ns \\
\hline \multicolumn{5}{|l|}{ AXILLARY SURGERY } \\
\hline NO AXILLARY SURGERY & $5(12,5 \%)$ & Ref & & \\
\hline SENTINEL NODE BIOPSY & $31(17,2 \%)$ & 1,46 & $0,49-4.60$ & ns \\
\hline AXILLARY LYMPH NODE DISSECTION & $46(20,1 \%)$ & 1,76 & $0,61-5,43$ & ns \\
\hline \multicolumn{5}{|l|}{ NEOADJUVANT CHEMOTHERAPY } \\
\hline NO NEOADJUVANT TREATMENT & $76(17,4 \%)$ & Ref & & \\
\hline NEOADJUVANT CHEMOTHERAPY & $6(46,1 \%)$ & 4,06 & $1,17-13,92$ & $<0,05$ \\
\hline \multicolumn{5}{|l|}{ TNM STAGE } \\
\hline IN SITU & $4(23,5 \%)$ & & & \\
\hline I & $27(16,1 \%)$ & Ref & & \\
\hline$\|$ & $25(13,9 \%)$ & 0,84 & $0,45-1,58$ & ns \\
\hline III & $8(20,5 \%)$ & 1,35 & $0,51-3,49$ & ns \\
\hline IV & $1(25 \%)$ & 1,74 & $0,07-19,99$ & ns \\
\hline UNKNOWN & $17(41,5 \%)$ & & & \\
\hline \multicolumn{5}{|l|}{ BMI } \\
\hline$<20$ & $1(25 \%)$ & 2,06 & $0,08-25,85$ & ns \\
\hline $20-25$ & $12(14 \%)$ & Ref & & \\
\hline
\end{tabular}


Table 3 Association between patient, tumor characteristics, treatment and occurrence of postoperative complications. (Continued)

\begin{tabular}{lllll}
\hline$>25$ & $31(23 \%)$ & 1,84 & $0,84-4,08$ & ns \\
\hline UNKNOWN & $38(17 \%)$ & & & \\
\hline SMOKING AT TIME OF DIAGNOSIS & & Ref & & \\
\hline NO & $46(16,7 \%)$ & 2,75 & $1,14-6,54$ & $<0,05$ \\
\hline YES & $11(35,5 \%)$ & & \\
\hline UNKNOWN & $25(17,6 \%)$ & & \\
\hline
\end{tabular}

Table 4 Survival analyses for one or more postoperative complications versus no postoperative complications.

\begin{tabular}{llllll}
\hline & DEATHS & 5-YEAR SURVIVAL (\%) & HR & 95\% Cl & p value \\
\hline OVERALL SURVIVAL & 133 & 70 & & & \\
\hline No postoperative complications & 91 & 75 & Ref & & \\
\hline Postoperative complications & 42 & 49 & 2,06 & $1,52-2,70$ & $<0,001$ \\
\hline
\end{tabular}

complications, which might be explained by missing values in about $50 \%$ of patients, since BMI registration in a chart may not be missing at random.

Since elderly patients are rarely included in clinical trials [12], large cohort studies are of great importance in this population. These studies are a good way of studying complications of treatment, since data are unbiased and the studies generally contain more patients [21].

This study also has some limitations. Due to the retrospectively collection of data, there might have been an underestimation of the number of complications. However, in these data, $18.2 \%$ of patients developed at least one complication, and this is even higher than a recent study in a large cohort in the U.S. [20] which reported a 30-day morbidity rate for all breast cancer procedures of $5.6 \%$. The most common complications were wound infections. Therefore, these data seem to accurately reflect general practice and correspond with previous studies.

A meta-analysis has confirmed that hormonal treatment as monotherapy is inferior to surgery (with or without hormonal treatment) for the local control and progression-free survival of breast cancer in medically fit older women [22-25].

However, in Italy, elderly patients receive less surgery and more hormonal therapy as monotherapy than younger patients, even in lower stages of disease [4].

This suggests that patients might be undertreated due to fear of morbidity and mortality in breast cancer surgery. Although elderly patients with comorbidity do have a higher risk of postoperative complications, relative mortality was not higher in this group and therefore suggests that omitting surgery because of fear for treatment-related mortality is only justified in vulnerable elderly patients. The question remains how to identify this specific group. Therefore, future prospective studies are needed to identify patients at risk for postoperative complications, and to develop tailored care for elderly breast cancer patients.

List of abbreviations

BMl: body mass index

Competing interests

The authors declare that they have no competing interests.

Authors' contributions

N.R, C.R: conception and design, interpretration of data, given final approval of the version to be published.

G.P, G.R, R.C, M.D: acquisition of data, drafting the manuscript, given final approval of the version to be published

A.A, B.A: critical revision, interpretation of data, given final approval of the version to be published

\section{Authors' information}

NR: PhD in Thoracic Surgery at University of Milan.

CR: Specialist in General Surgery, Cardinale Ascalesi Hospital of Naples.

GP: Resident in Geriatrics at University Federico II of Naples.

GR: Resident in Cardiology at University Federico II of Naples.

R.C.: doctoral fellow in Surgery at University Federico II Naples.

MD: Aggregate Professor of Surgery at University "Federico II" of Naples.

AA: Specialist in General Surgery, University Federico II of Naples.

BA: Associate Professor of Surgery at University "Federico II" of Naples.

\section{Declarations}

Publication of this article has come from personal funds.

This article has been published as part of BMC Surgery Volume 13 Supplement 2, 2013: Proceedings from the 26th National Congress of the Italian Society of Geriatric Surgery. The full contents of the supplement are available online at http://www.biomedcentral.com/bmcsurg/supplements/13/S2.

\section{Authors' details}

${ }^{1}$ Department of Biomedical, Surgical and Dental Sciences, University of Milan, Milan, Italy. ${ }^{2}$ Department of General Surgery, Cardinale Ascalesi Hospital ASL NA1, Naples, Italy. ${ }^{3}$ Dept. of Translational Medical Sciences, University "Federico II" of Naples, Naples, Italy. "Department of General, Geriatric, Oncologic Surgery and Advanced Technologies, University "Federico II" of Naples, Naples, Italy.

Published: 8 October 2013 
References

1. Wildiers H, Kunkler I, Biganzoli L, Fracheboud J, Vlastos G, Bernard-Marty C Hurria A, Extermann M, Girre V, Brain E, Audisio RA, Bartelink H, Barton M, Giordano SH, Muss H, Aapro M: Management of breast cancer in elderly individuals: recommendations of the International Society of Geriatric Oncology. Lancet Oncol 2007, 8(12):1101-15.

2. Guralnik JM: Assessing the impact of comorbidity in the older population. Ann Epidemiol 1996, 6(5):376-80

3. Braithwaite D, Satariano WA, Sternfeld B, Hiatt RA, Ganz PA, Kerlikowske K, Moore DH, Slattery ML, Tammemagi M, Castillo A, Melisko M, Esserman L, Weltzien EK, Caan BJ: Long-term prognostic role of functional limitations among women with breast cancer. J Natl Cancer Inst 2010, 102(19):1468-77

4. Bastiaannet E, Liefers GJ, de Craen AJ, Kuppen PJ, van de Water W, Portielje JE, van der Geest LG, Janssen-Heijnen ML, Dekkers OM, van de Velde CJ, Westendorp RG: Breast cancer in elderly compared to younger patients in the Netherlands: stage at diagnosis, treatment and survival in 127,805 unselected patients. Breast Cancer Res Treat 2010, 124:801-807.

5. van de Water W, Markopoulos C, van de Velde CJ, Seynaeve C, Hasenburg A, Rea D, Putter H, Nortier JW, de Craen AJ, Hille ET, Bastiaannet E, Hadji P, Westendorp RG, Liefers GJ, Jones SE: Association between age at diagnosis and disease-specific mortality among postmenopausal women with hormone receptor-positive breast cancer. JAMA 2012 307(6):590-7.

6. Biganzoli L, Wildiers H, Oakman C, Marotti L, Loibl S, Kunkler I, Reed M, Ciatto S, Voogd AC, Brain E, Cutuli B, Terret C, Gosney M, Aapro M, Audisio R: Management of elderly patients with breast cancer: updated recommendations of the International Society of Geriatric Oncology (SIOG) and European Society of Breast Cancer Specialists (EUSOMA). Lancet Oncol 2012, 13(4):e148-60.

7. NCCN Guidelines Version 1. 2013; Senior Adult Oncology. 2013 [http:// www.nccn.org/professionals/physician_gls/pdf/senior.pdf], Accessed.

8. Van de Water W, Bastiaannet E, Dekkers OM, de Craen AJ, Westendorp RG, Voogd AC, van de Velde CJ, Liefers GJ: Adherence to treatment guidelines and survival in patients with early-stage breast cancer by age at diagnosis. Br J Surg 2012, 99(6):813-20.

9. Lavelle K, Todd C, Moran A, Howell A, Bundred N, Campbell M: Nonstandard management of breast cancer increases with age in the UK: a population based cohort of women $>$ or $=65$ years. Br $J$ Cancer 2007, 96(8):1197-203.

10. Louwman WJ, Janssen-Heijnen ML, Houterman S, Voogd AC, van der Sangen MJ, Nieuwenhuijzen GA, Coebergh JW: Less extensive treatment and inferior prognosis for breast cancer patient with comorbidity: a population-based study. Eur J Cancer 2005, 41(5):779-85.

11. Land LH, Dalton SO, Jensen MB, Ewertz M: Impact of comorbidity on mortality: a cohort study of 62,591 Danish women diagnosed with early breast cancer, 1990-2008. Breast Cancer Res Treat 2012, 131(3):1013-20.

12. Zulman DM, Sussman JB, Chen X, Cigolle CT, Blaum CS, Hayward RA: Examining the evidence: a systematic review of the inclusion and analysis of older adults in randomized controlled trials. J Gen Intern Med 2011, 26(7):783-90

13. Vitug AF, Newman LA: Complications in breast surgery. Surg Clin North Am 2007, 87(2):431-51.

14. Pilotto A, Addante F, Franceschi M, Leandro G, Rengo G, D'Ambrosio P, Longo MG, Rengo F, Pellegrini F, Dallapiccola B, Ferrucci L: Multidimensional Prognostic Index based on a comprehensive geriatric assessment predicts short-term mortality in older patients with heart failure. Circ Heart Fail 2010, 3(1):14-20.

15. Houterman S, Janssen-Heijnen ML, Verheij CD, Louwman WJ, Vreugdenhil G, van der Sangen MJ, Coebergh JW: Comorbidity has negligible impact on treatment and complications but influences survival in breast cancer patients. Br J Cancer 2004, 90(12):2332-7.

16. World Health Organization (1992): The ICD-10 classification of mental and behavioural disorders.1-267, WHO, Geneva.

17. Patnaik JL, Byers T, Diguiseppi C, Denberg TD, Dabelea D: The influence of comorbidities on overall survival among older women diagnosed with breast cancer. J Natl Cancer Inst 2011, 103(14):1101-1111.

18. Dignam JJ, Huang L, Ries L, Reichman M, Mariotto A, Feuer E: Estimating breast cancer-specific and other-cause mortality in clinical trial and population-based cancer registry cohorts. Cancer 2009, 115(22):5272-83.
19. Winther Lietzen L, Cronin-Fenton D, Garne JP, Kroman N, Silliman R, Lash TL: Predictors of re-operation due to post-surgical bleeding in breast cancer patients: a Danish population-based cohort study. Eur $J$ Surg Oncol 2012, 38(5):407-12.

20. de Blacam C, Ogunleye AA, Momoh AO, Colakoglu S, Tobias AM, Sharma R, Houlihan MJ, Lee BT: High body mass index and smoking predict morbidity in breast cancer surgery: a multivariate analysis of 26,988 patients from the national surgical quality improvement program database. Ann Surg 2012, 255(3):551-5.

21. Rispoli C, Rocco N, lannone L, Compagna R, De Magistris L, Braun A, Amato $B$ : Developing guidelines in geriatric surgery: role of the GRADE system. BMC Geriatrics 2009, 9(Suppl 1):A98.

22. Rocco N, lannone L, Rispoli C, De Vito D, Accurso A: Early breast cancer in elderly women: surgery or primary endocrine therapy? BMC Geriatrics 2010, 10(Suppl 1):A31.

23. Serra R, Buffone G, Perri P, Renne M, Amato B, de Franciscis S: Male breast cancer manifesting as Cephalic Vein Thrombosis in a 70-year-old patient. Ann Vasc Surg 2013, 13.

24. Rispoli C, Rocco N, lannone L, Compagna R, Cacciapuoti MT, Bellino A, Amato $B$ : Breast reconstruction in older women: A growing request. BMC Geriatrics 2009, 9(Suppl 1):A46.

25. Amato B, Rispoli C, lannone L, Testa S, Compagna R, Rocco N: Surgical margins of resection for breast cancer: Current evidence. Minerva Chirurgica 2012, 67(5):445-452.

doi:10.1186/1471-2482-13-S2-S25

Cite this article as: Rocco et al.: Breast cancer surgery in elderly patients: postoperative complications and survival. BMC Surgery 2013 13(Suppl 2):S25.

\section{Submit your next manuscript to BioMed Central and take full advantage of:}

- Convenient online submission

- Thorough peer review

- No space constraints or color figure charges

- Immediate publication on acceptance

- Inclusion in PubMed, CAS, Scopus and Google Scholar

- Research which is freely available for redistribution

Submit your manuscript at www biomedcentral.com/submit
Biomed Central 